\title{
Health incentive research and social justice: does the risk of long term harms to systematically disadvantaged groups bear consideration?
}

\author{
Verina Wild, ${ }^{1,2}$ Bridget Pratt $^{3,4}$
}

${ }^{1}$ Department of Philosophy, LMU, University of Munich,

Germany

${ }^{2}$ Institute of Biomedical Ethics and History of Medicine,

University of Zurich

Switzerland

${ }^{3}$ Department of International

Health, Johns Hopkins

Bloomberg School of Public

Health, USA

${ }^{4}$ School of Population and

Global Health, University of

Melbourne, Australia

Correspondence to

Dr $\vee$ Wild, Faculty of

Philosophy, Ludwig-

Maximilians-University Munich,

Geschwister-Scholl-Platz 1

Munich 80539, Germany;

v.wild@|rz.uni-muenchen.de

Received 23 December 2015

Revised 12 August 2016

Accepted 19 September 2016

Published Online First

12 October 2016

\section{ABSTRACT}

The ethics of health incentive research - a form of public health research-are not well developed, and concerns of justice have been least examined. In this paper, we explore what potential long term harms in relation to justice may occur as a result of such research and whether they should be considered as part of its ethical evaluation. 'Long term harms' are defined as harms that contribute to existing systematic patterns of

disadvantage for groups. Their effects are experienced on a long term basis, persisting even once an incentive research project ends. We will first establish that three categories of such harms potentially arise as a result of health incentive interventions. We then argue that the risk of these harms also constitutes a morally relevant consideration for health incentive research and suggest who may be responsible for assessing and mitigating these risks. We propose that responsibility should be assigned on the basis of who initiates health incentive research projects. Finally, we briefly describe possible strategies to prevent or mitigate the risk of long term harms to members of disadvantaged groups, which can be employed during the design, conduct and dissemination of research projects.

\section{INTRODUCTION}

Health incentives have become an important feature of public health efforts in high income countries and in international development. The goal is to "use the incentive as an intervention intended to produce better health outcomes for individual recipients or better public health outcomes for communities". ${ }^{1}$ Incentives for health promotion (eg, cash payments, vouchers, reductions in insurance fees) are provided to motivate recipients to adhere to a healthcare plan, utilise health services or modify their behaviour. The promotion of these lifestyle and behaviour changes have been heralded as key means of preventing and managing chronic diseases. ${ }^{2}$ Numerous research studies are currently underway to understand the effectiveness of health incentives for producing healthy behaviours and for utilising health services. ${ }^{3}$ For example, researchers are examining the effectiveness of conditional cash transfers compared with unconditional cash transfers. ${ }^{4}$

However, the ethics of health incentive research are not well developed. This reflects a general dearth of ethics scholarship on public health research and health systems research (HSR). ${ }^{5}$ Depending on the nature of the intervention, health incentive research may be classified as both types of research or solely as public health research. ${ }^{\mathrm{i}}$ So far, certain ethical issues have been suggested to arise during health incentive research, including whether provision of incentives:

- is likely to undermine or enhance participant autonomy,

- crowds out intrinsic motivations,

- exacerbates existing inequalities, where control groups are used,

- is relevant to existing health needs and serves to mitigate larger health inequalities in host communities,

- is sustainable over the long term. ${ }^{1}$

Some of these issues relate to justice but detailed analysis and guidance on how to navigate them are lacking. A recent systematic review of the literature on HSR ethics revealed that existing guidance primarily focuses on informed consent, with very little discussing concerns of justice. ${ }^{7}$ General consideration of what violations of justice can occur during health incentive research and how to address them, therefore, deserves much closer scrutiny.

In this paper, we will focus on the question of what potential long term harms to systematically disadvantaged groups may occur as a result of such

${ }^{i}$ Public health research focuses on disease prevention or health promotion. Public health interventions or programmes that are developed and tested, including incentives, can aim to reduce the risk of physical, chemical, social or behavioural determinants of illness. HSR aims to generate knowledge to enhance the performance of health systems as a whole in terms of their hardware and software components (eg, financing, human resources, governance and service delivery). Common interventions include (among others) new methods of creating demand for existing health services and output based payment mechanisms to boost staff productivity at health facilities. ${ }^{5}$ Hoffmann $e t a l,{ }^{6}$ (p.13) state that " $[\mathrm{t}]$ he overlap [of HSR] with population health research, however, is less clear, but likely includes research on the public health system and the delivery of nonpersonal public health programmes and interventions. Excluded from health systems research would be population health research's focus on measuring or describing health, examining the determinants of health status and outcomes and assessing the effects of specific health promotion interventions". 
research and whether they should be considered as part of its ethical evaluation. ${ }^{\text {ii, iii }}$ This potentially contentious question has largely not been explored and its answer is not obvious. The causal responsibility of individual research projects for such long term effects is debateable. Our particular focus reflects that concerns of social or relational justice have become a key feature in the ethics of public health. ${ }^{8-14}$ It has been argued that social justice is the foundational moral justification and commitment for public health. ${ }^{8}$ Public health as a field thus has a special interest in the effects of its research and practice on systematically disadvantaged groups and on reducing health disparities. Systematic disadvantage has been defined as experiencing large shortfalls on a cluster of high priority functionings or dimensions of wellbeing. These may include health, bodily integrity, affiliation, self-determination, respect, and sense and imagination. ${ }^{8} 15$ Proxies for systematic disadvantage include domination linked to group membership and poverty (ie, disparities in respect and disparities in resources). ${ }^{8}$

In this paper, we will (1) establish that long term harms to members of systematically disadvantaged groups may potentially arise as a result of health incentive interventions, (2) argue that the risk of these long term harms also constitutes a morally relevant consideration for health incentive research, (3) suggest who may be responsible for assessing and mitigating such risks and (4) briefly describe possible strategies for their mitigating the risk of long term harms. Here, the term 'long term harms' refers to harms that contribute to existing systematic patterns of disadvantage for groups. These harms eventuate when incentives alter social structures (norms, rules, policies) in ways that further increase deprivations (or widen disparities) in dimensions of wellbeing for those who are already disadvantaged (relative to those who are not). Since the harms contribute to entrenched patterns of disadvantage, their effects are harder to remedy. The increased deprivations or widened disparities are experienced on a long term basis, persisting even once an incentive research project ends. The harms can affect research participants and, where incentives are implemented post-study as part of a public health programme, members of systematically disadvantaged groups more broadly. Thus, the long term harms of incentive research (also) encompass the subsequent effects of implementation of incentives post-study.

\section{WHAT ARE THE POTENTIAL LONG TERM HARMS OF HEALTH INCENTIVE INTERVENTIONS?}

Before moving on to the ethics of research, in this section, we identify three categories of potential long term harms caused by health incentive interventions. These categories have been derived from the public health and public health ethics literature, ${ }^{\text {iv }}$ bearing in mind existing conceptual work on systematic disadvantage from social or relational theories of justice. These theories purport that harm eventuates when deprivation on a dimension(s) of wellbeing increases, disparities in levels of functioning on these dimensions widen and/or the mechanisms

\footnotetext{
${ }^{i i}$ As this paper is part of a special issue on health incentive interventions and justice, it does not consider this question in the context of public health research in general. However, we believe that our arguments may be applicable to any type of public health research project.

iii Other justice related questions, such as whether incentive programmes targeting unhealthy populations or underprivileged populations are unfair to already healthy populations or privileged populations, deserve attention too but are not the focus of this paper.

${ }^{\text {iv }}$ Many of these categories are derived from the scholarship of Kristin Voigt (eg, see Voigt). ${ }^{16-18}$
}

that cause deprivations or disparities are reinforced or perpetuated. ${ }^{819}$ Consequently, concern has to be directed towards societal processes of domination or oppression, such as stigmatisation, exclusion, powerlessness, exploitation, racism and gender bias, as they comprise mechanisms that cause deprivations or disparities (ibd.).

The existing literature on incentive programmes does suggest that these programmes can have positive effects, such as increasing health equity and self-determination and reducing stigmatisation of systematically disadvantaged groups. ${ }^{20-23}$ However, in this section, we are interested in existing evidence that incentives may also cause particular harms that potentially affect members of systematically disadvantaged groups. The following proposed categories are not an exhaustive list but comprise an initial typology of long term harms that can be generated by health incentive interventions. ${ }^{\mathrm{v}}$

\section{Exacerbation of existing population health inequalities}

Underlying incentive interventions is the view that personal responsibility is a key factor in the prevention of chronic diseases and for the decision to live a healthy life. In general, the notion of personal responsibility for health remains controversial. $^{24} 25$ More specifically, it has been argued that, in a socially unjust world, there exist inequalities in choice contexts-that is, there is an inequality in the mere possibility of making selfresponsible decisions for a healthy lifestyle, including the decision to participate in incentive programmes. ${ }^{16} 17242627$ Voigt has empirically demonstrated that these sorts of "unequal choice contexts' (see Voigt ${ }^{17}$ p.94) exist in both high income countries and low and middle income countries. She shows that smoking and the decision to quit is largely dependent on aspects of one's social environment that are beyond individual control. These include living in a neighbourhood that is economically disadvantaged, being the subject of targeted advertising and/or lacking access to good quality schools and health services. ${ }^{17}$

Based on this evidence, there seem to be inequalities in the primary choice for participating in and ultimately benefiting from ongoing incentive programmes. Systematically disadvantaged groups are often at risk of living in social environments that might promote their members' adoption of unhealthy lifestyles and impede their successfully changing their behaviour (in response to incentives). ${ }^{17}$ Members of these groups are thus at risk of facing multiple and complex constraints beyond their control on their individual choices for healthier lifestyles and use of health services. As noted by Schmidt $e t a l,{ }^{28}$ it is easier for wealthy people with a gym in their apartment building to change their exercise behaviour as part of an incentive programme than it is for systematically disadvantaged people who live in deprived areas, without access to a gym.

Such unequal choice contexts can result in harmful effects by exacerbating existing population health inequalities. ${ }^{28}$ Mixed method research with pregnant women, new mothers and service providers in the UK demonstrates that patients and health professionals think health incentives have the capacity to increase health inequalities for marginalised families, with those with very chaotic lifestyles being less likely to be aware of and

${ }^{\mathrm{v}}$ We emphasise that empirical work is necessary to capture what long term harms to socially disadvantaged groups eventuate after health incentive interventions in order to further develop the typology of harms proposed in this paper. Health incentive research can be used to monitor for such effects in order to provide the necessary data. 
able to engage with incentive provision. ${ }^{29}$ In Germany, health insurance companies have implemented various bonus programmes to either incentivise the uptake of preventive measures or to reduce the necessity of acute care. Braun et $a l^{30}$ have shown that the participation rate of the richest quintile of the German population in these bonus programmes is higher (19\%) than for the poorest quintile (11\%). ${ }^{27}$ Ultimately, the health gap between the rich and the poor can be widened because those who are already better off benefit more from incentive interventions.

The effect of widening health disparities is especially morally concerning where (as described above) the groups who do not benefit within a given population are already systematically disadvantaged. Where incentives have this effect, it is a clearcut case of long term harm. When the benefits are substantial, the disparities may become even more inequitable ${ }^{31}$; the health status of groups that are at the lower end of the social ladder might be at risk of moving even farther from groups at the higher end. Patterns of systematic disadvantage may become further entrenched as a result. Incentive interventions may be especially prone to this type of effect.

\section{Increasing disadvantaged groups' experience of powerlessness}

Voluntary incentive programmes are based on the principle that people can freely decide for or against participation. However, if someone is 'too poor to say no' to an incentive, ${ }^{18}$ implementation of an incentive programme might unjustly take advantage of the constraints and disadvantaging structures experienced by certain groups. Instead of offering a motivation or assistance to live a healthier life on a voluntary basis, the incentive programme might be viewed as the only option for receiving a certain benefit. ${ }^{28}$ Such a decision can hardly be seen as a preferred choice but rather as having no other choice. A just public health system should not generate entry into an incentive scheme in this way but should create conditions under which everyone has the opportunity to live a healthy, self-determined life. If systematically disadvantaged groups adopt a health promoting behaviour or use health services due to feeling they have no other choice, this might amplify their awareness of their lack of self-determination. This heightened sense of lack of choice can increase the general experience of powerlessness by those who are already disadvantaged and, in effect, reinforce a form of structural oppression with potential long term effects. ${ }^{19}$

\section{Manifestation of self-blame and stigmatisation in disadvantaged groups}

Health incentives reinforce the norm that the primary responsibility for health lies with individual choices and behaviours, which promotes the idea that changing individual behaviours is a key solution for improving population health. However, structural constraints-for example, living in an underprivileged environment-are often a key cause of unhealthy choices and behaviours. Failure to recognise these structural causes can result in feelings of failure to adopt healthy lifestyles, which in turn may lead to feelings of guilt, shame or self-blame because people attribute such failings to themselves. ${ }^{32}$

The difficulties for some to adopt healthier lifestyles and to seemingly 'act irresponsibly' despite incentives to behave otherwise might also lead to the manifestation or perpetuation of their stigmatisation by others. ${ }^{4} 182433$ A question that deserves further research is whether the incentive is generating the discriminatory effect or whether the effect is a consequence of health professionals' behaviour, occurring irrespective of the implementation of the incentive programme. But as long as there is reason to believe that incentive programmes may add to this effect, we argue that the risk of their doing so is a relevant consideration. If there is the potential that incentives create or reinforce stigmatisation and/or discrimination, they perpetuate mechanisms of oppression that cause deprivations in dimensions of wellbeing. They may also add to existing structures of stigmatisation and self-blame of already disadvantaged groups. In the aforementioned mixed method study by Thomson et al, some participants felt that incentives could "'stigmatise' and create 'polarisation' and 'discrimination'" between different groups of women (eg, those who breastfeed and those who formula feed). ${ }^{29}$ Where stigmatisation, discrimination and self-blame are effects of health incentive interventions, they affect certain social norms and relations. As a result, their effects can persist over the long term even though the particular intervention has come to an end.

\section{SHOULD THE RISK OF LONG TERM HARMS BE CONSIDERED IN HEALTH INCENTIVE RESEARCH?}

The previous section established what long term harms to systematically disadvantaged groups may eventuate due to health incentive interventions. Here, we argue that the risk of these harms constitutes a morally relevant consideration when designing and reviewing research projects, and we provide five reasons for this claim.

First, if a sufficient concern for systematic and long term harm to disadvantaged groups exists for health incentive interventions in general (and we have established that it does above), this concern demands some consideration of the risk of such harms during the conduct of health incentive research. This can hold, even if, for reasons of complexity, a direct and causal responsibility for such harms cannot be established with precision for a health incentive research project. This view is consistent with a growing acknowledgment of health research's social responsibility for its wider and long term effects. ${ }^{34} 35$

Second, general normative arguments have been made that an objective of HSR should be to promote health equity, which is an essential component of social justice. ${ }^{36}$ Such research has been identified as an essential means of reducing health disparities between and within countries by the WHO and at ministerial summits on health research. ${ }^{37} 38$ Significant knowledge deficits exist regarding what health system barriers are hindering the delivery and affordability of health services and what strategies are required for overcoming them, particularly for disadvantaged groups. HSR has the potential to address these knowledge deficits. Accordingly, HSR projects, and thus health incentive projects, are often conducted with the primary aim of reaching vulnerable groups and improving their access to existing health services. ${ }^{5}$ Given HSR's underlying objective, it seems especially vital to try and mitigate the risk of long term harms to systematically disadvantaged groups when health incentive research is conducted.

Third, as we have claimed above we, like many other scholars, deem social and relational justice to be a fundamentally important value in public health practice and research that deserves special protection if at risk. ${ }^{10-12} 839$

Fourth, it is morally necessary to address the risk of long term harms in health incentive research because incentive studies-in contrast with clinical trials-are typically conducted at the community or societal level and, as a result, where such risks eventuate, harms will occur across communities or societies. These effects might have a considerable and profound 
impact on population health and might result in far reaching shifts of social reality and moral norms. Thus, whether and how they ought to be dealt with deserves to be thoroughly examined, even if actors do not carry direct or causal responsibility for such shifts.

Fifth, the limited existing literature that specifically addresses whether long term harms should be considered in health behavioural or public health research also supports doing so. ${ }^{39-42}$ Willison et $a l^{39}$ for example, propose that public health initiatives should identify and develop plans for mitigating the risk of such potential long term harms prior to implementation.

\section{WHO IS RESPONSIBLE FOR ADDRESSING THE RISK OF LONG TERM HARMS IN HEALTH INCENTIVE RESEARCH?}

We have established that the risk of long term harms to systematically disadvantaged groups is a morally relevant consideration in health incentive research, and that-even if a direct or causal responsibility is difficult to establish-a moral responsibility exists to address them. The next question is who is responsible for addressing such risks. Is it the job of researchers and institutional review boards (IRBs), or do other actors have a role to play as well? Here, we draw attention to the fact that this responsibility has at least two components-risk assessment and risk mitigation. This is consistent with Willison et al, ${ }^{39}$ who implicitly include both dimensions throughout their approach.

The limited existing literature is divided on the question of who carries responsibility for considering research projects' risk of long term harms. Fleischman et $a l^{40}$ reject the idea that justice-related long term social implications, including perpetuation of stereotypes, increase of health disparities or weakening of social fabric, should be part of IRBs' evaluation of specific behavioural research proposals. In their view, this is consistent with US federal regulations. ${ }^{43}$ Fleischman et al's main argument is that well designed and important research might be precluded if potential long term consequences for wider populations or society in general are taken into account by individual IRBs. They also take the position that a national advisory board should be established to take up these questions more broadly if an IRB or one of its members has significant concerns for a health incentive intervention's long term social impact. However, this should not stop participant recruitment and conduct of individual research projects. ${ }^{40}$

Several authors have questioned Fleischman et al's approach and/or taken an opposing position. Some doubt that long term risks can be neatly separated from an IRBs' risk-benefit assessment of a given project. ${ }^{42} 44$ Willison et $^{3 l^{39}}$ argue that assessing the risk of long term harms should be within the remit of IRBs but do not provide an explanation as to why they think so. They also contend that such risks should be considered when planning and reviewing evidence-generating public health initiatives "by those who are developing the protocol" (see Willison et $a l{ }^{39}$ p.3). Similarly, Benya suggests that consideration of long term societal consequences should be part of researchers' social responsibility. ${ }^{41}$ The Ottawa Statement on the Ethical Design and Conduct of Cluster Randomized Trials states that IRBs should take the risk of exacerbating inequalities within clusters into account when assessing the risks and benefits of studies. ${ }^{45}$

We agree with Fleischman et $a l^{40}$ that there is a general responsibility at the political level to discuss whether and how incentive studies should be part of health system reforms and to initiate societal discussions on the matter. ${ }^{46}$ However, we argue that there is an additional responsibility to assess and mitigate the risk of long term harms during health incentive research, which should be assigned on the basis of who initiates individual research projects. In doing so, we rely on the principle of capacity to act, a common allocative principle, to identify who bears responsibility. ${ }^{47}$

There are (at least) four possible types of health incentive research, which give rise to two different allocations of responsibility to address the risk of long term harms to systematically disadvantaged groups (table 1). The first type of project consists of an initial test of a health incentive by researchers in a particular country. This type of study is small in scale and carried out in a modest number of host communities. The research study and intervention are designed by the research team. On generating evidence that the incentive has a positive health impact, researchers then decide to conduct a scale up study where they test whether the incentive is effective in additional host communities. These two types of projects are researcher initiated, and it therefore makes sense to allocate the responsibility of risk assessment to IRBs and researchers and the responsibility for risk mitigation to researchers during projects because they are best placed (ie, have control over the intervention and the requisite knowledge) to perform these tasks.

In HSR or public health research in general, studies are also often initiated and interventions designed by non-research actors (box 1). Governments initiate the testing or scale up of health incentives and then hire research teams to conduct the evaluation of their implementation in a subset of cities or districts within countries. Beyond these smaller scale projects, governments can also initiate nationwide rollouts of health incentives (or other health system interventions) and hire researchers to perform the evaluations. In both cases, governments and implementers have the most control over the intervention's design. Thus, governments and implementers should be responsible for assessing the risk of particular incentives having a harmful impact in the long term. Governments can potentially discharge their obligation through national ethics bodies, as they have the organisational structures, the expertise

Table 1 Who bears responsibility under different health incentive research scenarios?

\begin{tabular}{|c|c|c|c|c|}
\hline & \multicolumn{4}{|c|}{ Type of health incentive research study } \\
\hline & $\begin{array}{l}\text { Initial test of health } \\
\text { incentive by researchers }\end{array}$ & $\begin{array}{l}\text { Researcher initiated scale up of } \\
\text { health incentive to new communities } \\
\text { or districts }\end{array}$ & $\begin{array}{l}\text { Government initiated testing } \\
\text { or scale up of health incentive }\end{array}$ & $\begin{array}{l}\text { Evaluation of nationwide roll } \\
\text { out of health incentive }\end{array}$ \\
\hline $\begin{array}{l}\text { Responsibility for assessing possible } \\
\text { risk of long term harms }\end{array}$ & Researchers and IRBs & Researchers and IRBs & $\begin{array}{l}\text { Governments via national } \\
\text { ethics bodies, and } \\
\text { implementers }\end{array}$ & $\begin{array}{l}\text { Governments via national } \\
\text { ethics bodies, and } \\
\text { implementers }\end{array}$ \\
\hline $\begin{array}{l}\text { Responsibility for developing and } \\
\text { implementing strategies to mitigate } \\
\text { such risks }\end{array}$ & Researchers & Researchers & $\begin{array}{l}\text { Governments and } \\
\text { implementers }\end{array}$ & $\begin{array}{l}\text { Governments and } \\
\text { implementers }\end{array}$ \\
\hline
\end{tabular}


Box 1 Example of government initiated health incentive research.

- At the end of 1998, the Inter-American Development Bank approved a US\$45 million loan to the Honduran government to implement the second-phase of its 'programa de asignación familiar' (family allowance programme). As part of this programme, vouchers were distributed to poor households with the requirement that pregnant women, nursing mothers and children in beneficiary households make regular visits to health centres. The aim of introducing the vouchers was to increase use of antenatal and postnatal services by pregnant women and new mothers, and to increase the numbers of children accessing health services. The second phase of the programme increased the value of the household level vouchers and made receiving them contingent upon mothers in beneficiary households making five prenatal visits during their pregnancy and attending a post-partum checkup. Children were required to attend nutritional and health checkups.

- The Inter-American Development Bank loan set aside a substantial budget for an evaluation of the family allowance programme. This included both a baseline assessment and subsequent evaluation after 2 years. A research team from the London School of Hygiene and Tropical Medicine, Emory University (USA) and the Food Consumption and Nutrition Division, International Food Policy Research Institute (USA) undertook a programme effectiveness trial (randomised at the municipality level) in Honduras to assess the impact of the second phase of the maternal and child voucher programme. The programme was implemented and evaluated in 70 municipalities in the west of Honduras, with a total population of 660000 . Researchers had no control over the design of the intervention; their role was solely to evaluate it.

Source: Morris et al. ${ }^{48}$

and the human resources to assess such risks. Implementing agents are best placed to devise and enact strategies to minimise those risks.

Additionally, in the post-study period, responsibility for the impacts of health incentive programmes would seem to shift to those undertaking their implementation, particularly where the incentive is implemented in an area beyond the original research site(s). Governments, NGOs or companies can be actors who decide to keep implementing and/or scale up incentive interventions post-study, so the onus then falls on them to assess the risks of doing so. It is therefore suggested that researchers' responsibilities stop soon after the research ends, assuming that they have already designed interventions to reduce the risk of long term harms and developed plans to mitigate those risks. It is then up to governments, NGOs and other implementers to continue on with those plans or to develop new ones. ${ }^{\mathrm{vi}}$ We thus propose a continuum of responsibility for long term harms so that responsibility taking is ensured from the start of incentive research projects to the wide scale implementation of successful incentives.

${ }^{\text {vi }}$ Researchers do, however, have a role in promoting the effective handover of the plans' implementation to these actors.
It might be argued that responsibility should be assigned based on an alternative principle, such as contribution to harm. That principle maintains agents' responsibility to address a harm derives from the extent to which they have contributed to bringing the harm in question about. ${ }^{47}$ However, relying on the principle of contribution does not seem to be the appropriate choice in this instance because the harms have not yet eventuated. The responsibility is rather to identify and mitigate the risk of long term harms, which we propose should be allocated to those who are best positioned to do so. Where strategies of mitigation fail, then it may be more appropriate to assign the responsibility to remedy harms based on contribution. Yet, as previously noted, establishing direct and causal responsibility for long term harms will be difficult. Assigning the responsibility to remedy long term harms based on capacity to assist or another principle may therefore be a better option.

\section{UPHOLDING OBLIGATIONS TO ADDRESS LONG TERM HARMS IN PRACTICE}

In order to minimise the risk of long term harms, researchers and IRBs, or national ethics bodies and implementers, should first undertake an assessment of whether the risk of harm across any of the aforementioned three categories (and others if detected in empirical studies) might apply in the context of particular research projects. Certain studies may be prevented on the basis of significant risk of long term harms to systematically disadvantaged groups. To make this determination, possible risks should be weighed against possible benefits of the research. Where studies test a control intervention, possible long term harms (and benefits) of both the experimental and control interventions should be considered. Here, we further note the complexity of incorporating the risk of long term harms into overall risk-benefit calculations of health research and highlight that it is an area that requires further investigation. This investigation is necessary to develop guidance to help researchers and IRBs determine when to prevent studies that generate significant risk of long term harms.

In most cases where risk of long term harms to systematically disadvantaged groups is identified, studies will probably proceed. Strategies will then need to be devised and implemented in these studies to mitigate such risks. The measures employed should aim to reduce the likelihood that incentives will reinforce mechanisms of oppression, such as stigmatisation, exclusion, self-blame and/or to increase the likelihood that they will empower disadvantaged groups by, for example, expanding their choice contexts. A preliminary list of options is presented below, but we acknowledge further work is needed to develop these measures. What options are appropriate will vary by the type of incentive under study and the risks it poses to systematically disadvantaged groups. General measures to employ might consist of the following.

- Examining the wider context of the study. For example, considering whether attending the incentivised health service or adopting the incentivised behaviour requires access to a certain level of education and/or certain resources that might be difficult for members of disadvantaged groups to achieve in the first place.

- Selecting inclusion and exclusion criteria for the study in a way that ensures participation of systematically disadvantaged groups. For example, criteria should not exclude participants with a low educational level, who live in deprived areas and/ or who do not speak the primary language of the study area. If so, using alternative criteria that promote the inclusion of one or more of such groups should be considered. 
- Including incentives that are accessible for underprivileged groups. For example, studies should not offer vouchers that are only redeemable in shops (or for goods) mainly frequented (or purchased) by the affluent. They should also be redeemable in shops (or for goods) frequented by the poor.

- Developing and using mechanisms (eg, surveys or interviews) to monitor incentives' effects on health disparities, discrimination, self-determination, exclusion and stigmatisation during the study, and to monitor incentives' effects post-study.

- Describing in study-related reports and publications how the risk of long term harms to systematically disadvantaged groups was successfully mitigated and the challenges that were encountered in doing so in order to inform future health incentive research and implementation.

If no special measures are implemented, researchers should justify why they do not consider them necessary. Monitoring incentives' effects on mechanisms of oppression and dimensions of wellbeing will be especially useful, as it will generate much needed evidence on what long term harms eventuate in health incentive research. That evidence can then inform risk assessments in future studies.

\section{DISCUSSION}

It might be suggested that the categories of harm we identify are morally distinct from one another. Some incentives might cause systematic disadvantage by increasing deprivations in selfdetermination or by widening health disparities. Where incentives reinforce or perpetuate mechanisms of oppression, they support processes that generate deprivations or disparities but do not directly cause them. This means the categories may be divided into direct and indirect harms. Thus, the moral badness of long term harms may vary; more work should be done to explore this (and other) moral distinctions between the different categories of harm.

It might also be argued that responsibility for addressing the risk of long term harms is too burdensome. However, we are not claiming that risk of long term harms to systematically disadvantaged groups must be eliminated entirely by the approach we present, and we also do not claim that researchers have an unlimited liability for all possible future harms to systematically disadvantaged groups. Furthermore, the complex effects of incentive research on systematically disadvantaged groups may often not be foreseeable and may even only become visible after the research has been conducted. Hence, we moderately claim that researchers, implementers and governments have a moral responsibility to make a robust effort to design and conduct incentive research in ways that minimise the long term harms with which we are concerned. Their capacity to identify risk of long term harms will be strengthened as more evidence of what harms eventuate is collected through the proposed monitoring measures.

Finally, one might claim that some of the recommendations we present resemble existing research guidelines. However, ethical guidance for research projects has focused primarily on the regulation of clinical trials. It has typically required assessing the risk of harms to individuals (eg, medical harms, privacy related harms) rather than the risk of social and relational harms to disadvantaged groups. The ethics of HSR and public health research is not well regulated yet and poses new questions, especially in the area of justice. ${ }^{49}$ No well established formal guidance documents exist for researchers or IRBs on HSR and public health research ethics. Of the few guidance documents that relate to HSR or public health research methods (ie, cluster trials), only the Ottawa Statement requires risk assessments to include one of the harms we identify, but it does not articulate strategies to mitigate the risk of studies exacerbating inequalities. ${ }^{45}$ The most prominent guidelines in the area of public health research, the CIOMS guidelines for epidemiological research (which are currently under revision), does not explicitly discuss risk of long term harms. ${ }^{50} 51$ Our list of measures to mitigate the risk of long term harms thus constitutes an initial proposal that can inform future development of HSR and public health research ethics guidelines. These measures may be especially relevant for incentive studies - the area which we have investigated in detail-but further research might show that our list of options can be useful for HSR and public health research in general.

\section{CONCLUSIONS}

Conduct of health incentive research is rapidly growing in countries worldwide, as health incentives are seen as a potentially effective means of preventing non-communicable diseases, maternal mortality and infant mortality. While we have acknowledged that such research can have positive effects for systematically disadvantaged groups, we have primarily focused on showing that such research can bring with it (at least) three categories of potential harms that may be disproportionately born by members of these groups and that need to be weighed against potential benefits for them. We argue that such risks should be assessed and mitigated as part of individual research projects' design and ethical review, with the responsibility for doing so varying according to who initiates a given study. Social and relational justice is a fundamentally important value in public health practice and research, and it deserves special protection if at risk. We have suggested a number of general measures to mitigate the risk of long term harms to systematically disadvantaged groups in health incentive research, but further work is needed to develop appropriate strategies. Beyond minimising the risk of long term harms, a further question to explore is whether health incentive research should aim to create benefits for systematically disadvantaged groups in terms of wellbeing and empowerment. Perhaps incentive studies should not only aim to minimise risks for systematically disadvantaged groups but also aim to actively find ways to increase benefits for these groups with the help of the tested intervention. Future research should consider positive obligations associated with health incentive research to such groups as a matter of social justice.

Acknowledgements Many thanks to the collaborating group at LMU Munich, especially to Fiorella Battaglia, Alexander Hevelke and Julian Nida-Rümelin, and to the Consortium of the EU FP7 Research Project Credits4Health. Parts of this paper were presented at the conference 'The ethics of health incentive programmes', LMU Munich, December 2014, and at a research seminar at the Philosophy Department of the University of Gothenburg in May 2015. We would like to thank the audience at both events for helpful comments. We wish to express our gratitude to Orsolya Friedrich, Corinna Klingler and Kristin Voigt for their valuable comments on draft versions of this paper.

Contributors Both authors meet all four required criteria: substantial contributions to the conception or design of the work; or the acquisition, analysis or interpretation of data for the work; and drafting the work or revising it critically for important intellectual content; and final approval of the version to be published; and agreement to be accountable for all aspects of the work in ensuring that questions related to the accuracy or integrity of any part of the work are appropriately investigated and resolved. VW had the idea for the paper and wrote the first draft.

Funding Australian National Health and Medical Research Council (NHMRC) Early Career Sidney Sax Public Health Overseas Fellowship, 1052346. The research leading to this paper has received funding from the European Union's Seventh Framework Programme FP7/2007-2013 under Grant Agreement no. 602386 Credits4Health. 
Disclaimer The contents of this article are solely the responsibility of the authors and do not reflect the views of the NHMRC.

Competing interests None declared.

Provenance and peer review Not commissioned; externally peer reviewed.

\section{REFERENCES}

1 London AJ, Borasky DA Jr, Bhan A, et al. Ethics Working Group of the HIV Prevention Trials Network. Improving ethical review of research involving incentives for health promotion. PLoS Med 2012;9:e1001193.

2 WHO. Innovative Care for Chronic Conditions. Building Blocks for Action. Globa Report. Geneva: WHO, 2002. http://www.who.int/chp/knowledge/publications/ icccglobalreport.pdf?ua=1 (accessed Jul 2016).

3 Mitchell MS, Goodman JM, Alter DA, et al. Financial incentives for exercise adherence in adults: systematic review and meta-analysis. Am J Prev Med 2013;45:658-67.

4 Pega F, Shaw C, Rasanathan K, et al. Climate change, cash transfers and health. Bull World Health Organ 2015;93:559-65.

5 Hyder AA, Rattani A, Krubiner $C$, et al. Ethical review of health systems research in low- and middle-income countries: a conceptual exploration. Am J Bioeth 2014;14:28-37.

6 Hoffman S, Röttingen J-A, Bennett S, et al. Background Paper on Conceptual Issues Related to Health Systems Research to Inform a WHO Global Strategy on Health Systems Research. 2012. Available from: http://www.who.int/alliance-hpsr/ alliancehpsr_backgroundpaperhsrstrat1.pdf (accessed Jul 2016).

7 Ali J, Pratt B. Scoping review on the ethics of health policy and systems research. Presentation at Joint WHO Meeting on Ethics Guidance for Health Policy and Systems Research; Switzerland: University of Zurich, 2015.

8 Powers M, Faden R. Social justice: the moral foundations of public health and health policy. Oxford: Oxford University Press, 2006. 246 p.

9 Gostin LO, Powers M. What does social justice require for the public's health? Public health ethics and policy imperatives. Health Aff (Millwood) 2006;25:1053-60.

10 Anderson ES. What is the point of equality? Ethics 1999;109:287-337.

11 Daniels N. Just health care. New York: Cambridge University Press, 1985. 264 p.

12 Ruger JP. Health and social justice. Oxford: Oxford University Press, 2010. 224 p.

13 Braveman P, Gruskin S. Defining equity in health. J Epidemiol Community Health 2003:57:254-8.

14 Venkatapuram S. Health justice: an argument from the capabilities approach. Oxford: Wiley, 2011. 288 p.

15 Wolff J, de-Shalit A. Disadvantage. Oxford: Oxford University Press, 2007. 244 p.

16 Voigt K. Incentives, health promotion and equality. Health Econ Policy Law 2012;7:263-83.

17 Voigt K. Smoking and social justice. Public Health Ethics 2010;3:91-106

18 Voigt K. Too poor to say no? Health incentives for disadvantaged populations. J Med Ethics 2016; doi:10.1136/medethics-2016-103384

19 Young IM. Justice and the politics of difference. Princeton: Princeton University Press, 1990. 300 p.

20 Oliver A. Can financial incentives improve health equity? BMJ 2009;339:b3847.

21 Burr ML, Trembeth J, Jones KB, et al. The effects of dietary advice and vouchers on the intake of fruit and fruit juice by pregnant women in a deprived area: a controlled trial. Public Health Nutr 2007;10:559-65.

22 Wolff J. Paying people to act in their own interests: incentives versus rationalization in public health. Public Health Ethics 2015:8:27-30.

23 Gorin M, Schmidt H. "I Did It For the Money": incentives, rationalizations and health. Public Health Ethics 2015;8:34-41.

24 Voigt K. Appeals to individual responsibility for health. Camb Q Healthc Ethics 2013;22:328-9.

25 Wikler D. Personal and social responsibility for health. Ethics Int Aff 2002:16:47-55.

26 Bishop G, Brodkey AC. Personal responsibility and physician responsibility-West Virginia's Medicaid plan. N Engl J Med 2006;355:756-8.

27 Schmidt H, Gerber A, Stock S. What can we learn from German health incentive schemes? BMJ 2009;339:b3504.
28 Schmidt H, Voigt K, Wikler D. Carrots, sticks, and health care reform-problems with wellness incentives. N Engl J Med 2010;362:e3.

29 Thomson G, Morgan H, Crossland N, et al. Unintended consequences of incentive provision for behaviour change and maintenance around childbirth. PLOS ONE 2014;9:e111322

30 Braun B, Reiners $H$, Rosenwirth $M$, et al. Anreize zur Verhaltenssteuerung im Gesundheitswesen. Effekte bei Versicherten und Leistungsanbietern. Bertelsmann Stiftung. 2006. http://www.bertelsmann-stiftung.de/fileadmin/files/BSt/Publikationen/ GrauePublikationen/GP Anreize zur Verhaltenssteuerung im Gesundheitswesen. pdf (accessed Jul 2016)

31 Schmidt H. Wellness incentives, equity, and the 5 groups problem. Am J Public Health 2012:102:49-54.

32 Guttman N, Ressler WH. On being responsible: ethical issues in appeals to personal responsibility in health campaigns. J Health Commun 2001;6:117-36.

33 Popay J. Should disadvantaged people be paid to take care of their health? No. BMJ 2008:337:a594

34 Weil V. Making sense of scientists' responsibilities at the interface of science and society. Commentary on "Six Domains of Research Ethics". Sci Eng Ethics 2002;8:223-7

35 Zwart H, Landeweerd L, van Rooij A. Adapt or perish? Assessing the recent shift in the European research funding arena from "ELSA" to "RRI". Life Sci Soc Policy 2014;10:11.

36 Pratt B, Hyder AA. Global justice and health systems research in low- and middle-income countries. J Law Med Ethics 2015;43:143-61.

37 WHO Task Force on Health Systems Research. The Millennium Development Goals will not be attained without new research addressing health system constraints to delivering effective interventions. 2005. http://www.who.int/rpc/summit/Task_Force on HSR 2.pdf (accessed Jul 2016).

38 Ministerial Summit on Health Research. The Mexico statement on health research. Mexico City, 2004. http://www.who.int/rpc/summit/agenda/en/mexico_statement_ on health research.pdf (accessed Jul 2016).

39 Willison DJ, Ondrusek N, Dawson A, et al. What makes public health studies ethical? Dissolving the boundary between research and practice. BMC Med Ethics 2014;15:61.

40 Fleischman A, Levine C, Eckenwiler L, et al. Dealing with the long-term socia implications of research. Am J Bioeth 2011:11:5-9.

41 Benya $F$. The need for topically focused efforts to deal with the long-term social implications of research. Am J Bioeth 2011;11:19-20.

42 Wasserman D. Challenges in a divided assessment of the social benefits and risks of research. Am J Bioeth 2011;11:12-13.

43 US Department of Health and Human Services. Code of Federal Regulations. Protection of Human Subjects. § 46.11114 July 2009. http://www.hhs.gov/ohrp/ humansubjects/guidance/45crr46.html\#46.111 (accessed Jul 2016).

44 White GB. Designing a disconnect? Am J Bioeth 2011:11:20-2.

45 Weijer C, Grimshaw JM, Eccles MP, et al. The Ottawa statement on the ethical design and conduct of cluster randomized trials. PLoS Med 2012;9: e1001346.

46 Evans $\mathrm{JH}$. Power and representation of the public's values in a social implications of research commission. Am J Bioeth 2011;11:10-11.

47 Barry C, Raworth K. Access to medicines and the rhetoric of responsibility. Ethics Int Aff 2002;16:57-70

48 Morris SS, Flores R, Olinto $\mathrm{P}$, et al. Monetary incentives in primary health care and effects on use and coverage of preventive health care interventions in rural Honduras: cluster randomised trial. Lancet 2004;364:2030-7.

49 Barrett DH, Ortmann LH, Brown N, et al. Public health research. In: Barrett DH, Ortmann LH, Dawson A, et al, eds. Public health ethics: cases spanning the globe. Springer International Publishing, 2016:285-318.

50 Lee LM. Public health ethics theory: review and path to convergence. J Law Med Ethics 2012;40:85-98.

51 CIOMS. International Ethical Guidelines for Biomedical Research Involving Human Subjects. 2002. http://www.cioms.ch/publications/guidelines/guidelines_nov_2002_ blurb.htm (accessed Jul 2016). 